\title{
The Effect of Translating English into First Language in EFL Classroom: The Case of Two Secondary Schools
}

\author{
Tegbar Kibret Muluneh \\ Department of English Language and Literature, College of Social Sciences and Humanities, \\ Ambo University, Ethiopia
}

\begin{abstract}
The main objective of this study was to investigate the effects of translating English into the students' first language on students' learning of English at the two selected secondary schools. For selecting participants of this study, simple random sampling technique was employed. Accordingly, one hundred eleven students and three English language teachers' were selected from the two schools as participant of the study. Five data gathering instruments namely, observation, questionnaire, focus group discussion, interview and audio-taped lessons were used to collect the data. To analyze the responses given through each tool, descriptive survey method using frequency and percentages was employed. Results of the data show that both teachers and students have positive attitudes toward the use of translation except a few who reject it. Even if audio-taped lessons indicated some mismatch of translated sentences and the original English language versions, the majority of sample students further agreed that translation and L1 use helps them to make difficult concepts easy; to feel comfort; to feel at ease, and develop target language vocabularies. Based on the findings, it is also essential to design an English course considering the relative importance of translating English into the students' first language.
\end{abstract}

Keywords: Translation, Secondary School, Mixed-Methods, First Language

DOI: $10.7176 /$ JLLL/61-02

Publication date:October $31^{\text {st }} 2019$

\section{INTRODUCTION}

According to [1], the use of students' first language in second or foreign language learning has been a point of argument. The question over whether English language classrooms should include or exclude the use of translation and the students' first language has also been a controversial issue for a long time. This disagreement has also been in the sample schools in that different teachers argued widely on the pros and cons of the use of translation on English language learning. However, both sides provided their own evidence for the argument they raised.

Opponents of the first language use mainly underestimate Krashen's theory that adults can learn a foreign or second language in the same way as children pick up their mother tongue, and so they believe that there is no need of translation between L1 and L2 [2]. But, the researcher assumes that it could be hard to say that adults can grasp all foreign or second language inputs unless they are put in a speech community. But, it is not to mean that adults couldn't learn foreign language, rather they are not as active as children do. Therefore, it needs further investigation and should be left for others. According to the above opponents, the fear that using L1 will interfere with L2 and its use also reduces students' exposure to the target language, are also further arguments put forward against the use of students' first language in the classroom.

As it was further noted by [1], acknowledging that using L1 has some drawbacks, supporters of the students' first language use, on the other hand, believe that the use of the students' first language has a supportive and facilitative role on learning and teaching of the target language. Therefore, the situation in the sample schools is not as such more different as what the literature shows. The school teachers frequently use the students' mother tongue, even though the Ministry of Education (MOE) offers books designed in English. Teachers of the sample schools use Amharic language as a medium of instruction in teaching the target language. Reading is taught using lengthy and difficult texts and sentences are often translated directly, with explicit focus on one-to-one translation both to and from the target language. This scenario shows that very little attention is given to pronunciation or creative production of the target language. This in turn, seems to provide a backdrop for the target language teaching methods to follow, because students who were taught through translation believed to face multi-faceted problems in the era of globalization. This, in turn, seems to be the reason why some English students are unable to cope with the existing situation in Universities and Colleges, because the domination of translation-based education in elementary and second cycle primary schools seems to limit the students' ability to master all language elements necessary for the academic achievements. Added to this, what could magnify the problem of the use of L1 in the L2 classroom instruction is that forms of any two languages may differ; it is almost impossible that any form of each language would communicate exactly the same message [3]. As a result, it seems to be a serious problem, as the researcher assumes in connection to [3]'s idea, for translators to use the target language forms to refer to the same things as the source language does. Likewise, students' first language structures and English structures are different and may in turn lead to false interpretation 
of the target language to the students' first language. From this evidence, what the writer of this paper likes to suggest is that teaching through translation could limit students' possible exposure to the target language practice because there seems to be no chance to develop English language vocabularies when students are taught through Amharic language, which is the working language of Ethiopia. Due to limited English vocabularies, teachers dominantly use Amharic language together.

Jimenez and Murphy (1984), in relation to Garret's (1986), cited in [3] argument, further stated that translation gives very little emphasis to the productive competencies necessary for communicative ability in a language and as a result, students of this method are claimed to almost universally exhibit deficiencies in their oral communicative abilities. As far as the researcher is concerned, there seems to be no difference, even between teaching the mother tongue and the target language because the majority of the English lesson periods are covered by teaching through translation into the students' first language (Amharic). In addition to this, when there is a group discussion, students frequently use the common language and they forget the target language that they are supposed to use while doing group works, because the structures learned through translation are of little or no use to the learner, as communicative ability is impeded through attention to form rather than attention to the meaning. Therefore, as different linguists argued, translation could have paramount effects on the teaching and learning processes of the target language in the sample schools.

Therefore, even though the growing numbers of researchers have considered the role of using translation in a foreign language teaching and learning, very little attention has been given, specifically to the effects of translating English into the learners' first language on learning of the target language, that is, the impact of translation on learning English. But, as long as the other related works in relation to the writer's study is concerned, no work has been conducted on the influences of translation on the students' learning of English in Amharic language context. Some related works like [1] study put emphasis on the examination of whether not using of the students' first language really exists in the context of Oromiffa (Oromo language, dominant language in Ethiopia). His study revealed that there was a positive attitude towards the use of Oromiffa. [1]'s work also used an attempt to examine whether this not using the students' L1 really exists at college level taking the first year major diploma students and English language instructors as a subject of his study. Unlike [1], the researcher used the two selected second cycle primary school students as a subject of his study. In fact, a work that was almost similar to the researcher's study was carried out by [4]. [4] generalizes that there was an over implementation of Amharic in the English language classrooms. However, differences exist between [4]'s paper and this study in research instruments, objectives and number of tools used. First, in contrast to [4]'s study, this work is not basically aimed to determine the extent to which teachers use Amharic language in English classroom. But it investigates the positions of teachers and students toward using translation in English classrooms in general and the effects of translating English into their first language on students' learning of English in particular. Second, [4] used only audio-tapped lessons dominantly to collect his data. But, the writer of this paper used the other four additional data collecting instruments (i.e. observation, focus group discussion, interview, and questionnaire) so as to avoid system bias more than that of [4] did. Third, the subjects in [4]'s study were four junior secondary school students and teachers but this study includes participants from the two selected high school students and English teachers. Having this gap in mind, this study attempted to investigate the effects of translating English into the students' first language (Amharic language in the case of this study) and investigated to what extent teachers use translation during teaching the target language (English). To this end, the following specific research questions were designed to be answered through investigating the problems of translation on the students' English language learning. (1) What are the effects of translating English into Amharic language on students' learning of English? (2) To what extent do teachers translate English into Amharic language? (3) What is the position held by students about the use of translation in English classroom? (4) What are the major problems encountered in translating English into Amharic language?

\section{MATERIAL AND METHOD}

In order to describe or delineate, analyze and specify naturally occurring phenomenon without experimental manipulation, descriptive survey method was used [5] in order to have a clear concept of the nature of the problem because descriptive survey method appears suitable for refining research tools, such as questionnaire, classroom observation, focus group discussion, semi-structured interview and audio-taped lessons. The relevance of this method for such purpose has been confirmed by [6], and [7].

\section{Participants of the Study}

The two selected high schools, namely, Mengesh Jembere and Shikudad secondary schools, found in Amhara regional state of Ethiopia, were selected as a focus of this study. The main aim of this study was to investigate the effects of translating English into the students' first language (Amharic language in this case) on students' learning of English at these selected high schools (namely, Mengesh Jembere and Shikudad secondary schools. For selecting students, simple random sampling technique was employed. Concerning the sample size, $15 \%$ of 
the total population of the students was selected so as to reflect the trait distribution that exists in the population. In this regard, fifty seven grade nine students were selected having the top-ten students from six sections as a sample from Mengesh Jembere secondary school. The same procedures were also followed to get sample students from Shikudad secondary School. In this regard, fifty four top-ten students were selected to complete the questionnaire out of 5 sections. Therefore, this study included seven hundred thirty five grade-nine students and six English teachers as a sample population from the two schools having eleven sections, six from Mengesh Jembere and five sections from Shikudad secondary schools. In this way, one hundred eleven sample students were selected from the two schools to fill the questionnaire.

\section{Data gathering Tools}

Five data gathering instruments namely, observation, questionnaire, focus group discussion, interview and audio-taped lessons were used to collect the data. Some classrooms were observed to assess the actual translation problems. A total of six consecutive English classroom observations were carried out including classes used for tape recorder in the two of the selected sample schools. [5] pointed out that descriptive data may be collected by observing the target language learning activity or behavior and noting only those aspects of the event which are of interest for the study. The main use of observation, as [5] ibid) further asserted, on collecting data is for examining a phenomena or a behavior while it is going on. To this end, an observation checklist was prepared and used so as to aid the task of observing the session. The predominant instrument employed for data collection from the sample students was the questionnaire. This is the popular, according to [8], means for collecting all kinds of data and the researcher found it convenient for this study as [8] stated. In this regard, a questionnaire consisting of both closed and open-ended types was administered to 111 top-ten students. In order to collect additional data and to triangulate the data obtained through the selected tools, three different English teachers' classroom lessons were audio-taped having one BA holder from two schools. In addition to this, interview with teachers and focus group discussions (FGD) with students were carried out to get the data that may appear difficult to get through other tools. To analyze the responses given through each tool, descriptive survey method using frequency and percentages was employed. The interviews were believed to be more relevant for this study for three major reasons: first, it was intended to generate deep information that may appear unnoticeable through other tools. Second, it was used as a supplementary data to information obtained through other tools. Third, interviewees feel free during talking on matters related to the effects of translation in the English classroom. FGD was also used in that students would bring necessary information led by the researcher and supported and encouraged by each other to express their views freely. The researcher also used this instrument to augment the data gathered through other instruments and to take an advantage of the synergetic effects of focused discussions with students who have had some common experiences. Lessons were also audio-taped so as to get rich data on the translation activities conducted in the classroom. To this end, three sections of grade 9 English lessons were audio-taped. Recordings were carried out to find out the translation problems encountered on the students' learning of English and the extent to which teachers translate English language (target language) into Amharic language. Another major purpose of this instrument was to analyze the lessons presented and translated in connection to the major criticisms forwarded against the use of translation and students' L1 in English classroom. Even though the researcher introduced teachers that observation and recordings were for the research purpose only, the exact objectives of this study were not disclosed. This was intended to prevent the problem of sensitizing teachers and students to show behavior different from the usual ones and by the help of this technique to get more natural data.

\section{Data Analysis}

The data collected were analyzed using simple percentages and frequencies (quantitatively) and narrative techniques (qualitatively). Simple percentage was used because the researcher found it relevant quantitative illustration because it is useful in simple explanation of basic differences or similarities that could exist between or among the variables under observation.

As the researcher tried to list down earlier, classroom observation, questionnaire and focus group discussion with students, interview with teachers and tape-recorded lessons were the five instruments used to gather appropriate data for the study. Based on these tools, the data were analyzed as follows:

Audio-taped lessons were changed into written form and analyzed in a narrative way so as to see the translation problem on the students' learning as stated by different scholars. The non-verbal features, such as gestures were not taken into consideration for analysis because they are not measurable. The results obtained from the students' questionnaire were tallied and the frequencies were changed into percentages. Percentage value was used based on the reasons mentioned in the introductory part of this sub-topic. The open-ended part of the questions, interview, observation and focus group discussion results were summarized and analyzed qualitatively. 


\section{RESULT AND DISCUSSION}

3.1. Results of the Students' Questionnaire

[Tables of item 1-5]: Students' Opinion on and Reasons for the Importance and Frequency of English Teachers' Translation Use

\begin{tabular}{|l|l|l|c|c|}
\hline $\begin{array}{l}\text { Item } \\
\text { no. }\end{array}$ & Questionnaire Items & Alternatives & Freq & \% \\
\hline 1. & $\begin{array}{l}\text { In your opinion, should English teacher use translation in the English } \\
\text { classroom at high school level? }\end{array}$ & A. yes & 92 & 82.9 \\
\cline { 2 - 5 } & B. no & 19 & 17.1 \\
\hline \multicolumn{2}{|l|}{ Total } & & $\mathbf{1 1 1}$ & $\mathbf{1 0 0}$ \\
\hline
\end{tabular}

As the data are presented in the above Table (Item 1), a considerable number of respondents $(92(82.9 \%)$ revealed that their English teacher should use translation while presenting English lesson. But only few respondents (19(17.1\%) selected 'No' answer. Therefore, what the data, in advance, indicates is that students have a positive attitude towards the teachers' use of translation while they learn English at a secondary school level.

\begin{tabular}{|l|l|l|l|l|}
\hline 2. & $\begin{array}{l}\text { If 'Yes', why do you think that the use of } \\
\text { translation is important in the English } \\
\text { classroom? Because: }\end{array}$ & $\begin{array}{l}\text { a. It helps me to understand difficult } \\
\text { concepts }\end{array}$ & 30 & 32.6 \\
\cline { 3 - 6 } & $\begin{array}{l}\text { b. It helps me to understand new } \\
\text { vocabulary items }\end{array}$ & 42 & 45.6 \\
\cline { 3 - 6 } & $\begin{array}{l}\text { c. It helps me to feel at ease, } \\
\text { comfort and less stressed }\end{array}$ & 20 & 21.8 \\
\cline { 2 - 6 } & d. If any other reasons, please specify & $\mathbf{9 2}$ & $\mathbf{1 0 0}$ \\
\hline
\end{tabular}

In case of Item 2, (30(32.6\%) of the respondents answered that teachers' use of translation in English class helps them to understand difficult concepts while other respondents $(42(45.6 \%)$ said that translation helps them to understand new vocabulary items. Another portion of the respondents $(20(21.8 \%)$ answered that translation use helps them to be less stressed, feel at ease and comfortable. This data verifies the [2] argument on the importance of the students' L1 use in that the positive role of the mother tongue has recurrently been acknowledged as a rich resource, which, if used judiciously can assist second language teaching. Judicious use theory in a sense, according to [2] teacher should use translation and the students' L1 at the time when all other means of clarifying the contents of the lessons are exhausted. Cook further noted that students' first language should be used only for concept checking; and to make students to comprehend the lessons. In connection to the above idea, students responded under option ' $\mathrm{D}$ ', that is, open-ended question as follows: students overwhelmingly revealed that as English is not their mother tongue, it has to be translated to their mother tongue (i.e. Amharic language). Students added that they even ask teachers to translate some difficult words and sentences into Amharic language; otherwise, as they responded, they could not understand what the teachers teach. In relation to all the above responses, students further argued that translation makes English language not to be strange to them. Moreover, translation makes students', as they answered, mind open and makes them know more and more English words. Furthermore, students expressed their opinion through open-ended question in that sometimes teachers should explain using only English language in such a way that they can get an opportunity to know how to speak in English, write, listen and read in it. This is not to mean, as they further noted, that translation sometimes is not important, but is the core point through which they can know new words, ideas, and to know the language very well and so on. Students, lastly, added that translation exercises students in English language. The position of students towards the use of translation had also been verified through the researcher's classroom observation because students become very happy when lessons become translated by their teacher. Otherwise, they keep silent in learning. Therefore, what we can conclude from the data is that translation has a paramount importance on the students' language learning.

\begin{tabular}{|l|l|l|l|l|}
\hline 3 & How often do you like your English teacher to translate English into & A. Frequently & 44 & 39.7 \\
\cline { 3 - 5 } & Amharic Language? & B. Sometimes & 40 & 36 \\
\cline { 3 - 5 } & & C. Rarely & 17 & 15.3 \\
\cline { 3 - 5 } & & D. Never & 10 & 9 \\
\hline \multicolumn{2}{|l}{} & 111 & 100 \\
\hline
\end{tabular}

According to item 3 in the above table, (44(39.7\%) of the students revealed that their English teachers should translate English into their mother tongue frequently while other noticeable number of students $(40)(36 \%)$ responded by advocating for English teachers to use translation sometimes. The remaining respondents $(17(15.3 \%)$ thought that it has no such a sounding importance for the classroom pedagogy and suggested translation use in rare cases. However, majority of students responded (as can be seen from option ' $a$ ' and ' $b$ 'Item 3 ) that translation should be used in English classes. 


\begin{tabular}{|l|l|l|l|l|}
\hline 4. & Does your English teacher use translation in English class? & A. Yes & 91 & 82 \\
\cline { 3 - 5 } & B. No & 20 & 18 \\
\hline Total & & $\mathbf{1 1 1}$ & $\mathbf{1 0 0}$ \\
\hline
\end{tabular}

In response to Item 4, majority of students (91(82\%) replied that their English teachers use translation in English classes. But the remaining imperceptible number of students $(20(18 \%)$ responded that English teachers do not use translation. However, it is reasonable to conclude that English teachers use translation while teaching English.

\begin{tabular}{|l|l|l|l|l|}
\hline 5 & If 'Yes', how often does he/she use it (say, in one lesson period)? & A. fairly frequently & 40 & 44 \\
\cline { 3 - 5 } & B. sometimes & 47 & 51.7 \\
\hline & C. rarely & 4 & 4.3 \\
\cline { 3 - 5 } & D. never & 0 & 0 \\
\hline \multicolumn{2}{|l|}{ Total } & & $\mathbf{9 1}$ & $\mathbf{1 0 0}$ \\
\hline
\end{tabular}

Some other considerable number of students responded to option 'a' and 'b' under Item 5. Hence, $(40(44 \%)$ of the students argued that their English teachers use translation fairly frequently while the other half of the students (47(i.e. 51.7\%) argued that their English teachers sometimes translate English language into Amharic language. This fact had also been observed from the classroom setting in that English teachers use translation while teaching. Audio-taped lessons can be taken as an evidence for this scenario. Thus, what we can conclude from the data presented under item 5 is that English teachers in the selected secondary schools translate the target language into Amharic language intentionally. For instance, the classroom observation results in relation to audio-taped lesson results indicated that English teachers write certain sentences on the chalk board and translate it into the students' first language. From this and the other data presented under the above items, such as items 1, 2,3 and 4, we can say that translation is the part and parcel of the students' English language learning and teachers' teaching in the selected schools.

[Tables from item 6-9]: Responses on the Position Held by Students towards the Use of Translation in English Classroom.

\begin{tabular}{|l|l|l|l|l|}
\hline Item no & Questionnaire Items & Altern-atives & Fr. & $\mathbf{\%}$ \\
\hline 6. & $\begin{array}{l}\text { Do you like to use translation in your present English } \\
\text { Periods? }\end{array}$ & a. yes & 70 & 63 \\
\cline { 3 - 6 } & b. no & 41 & 37 \\
\hline Total & & $\mathbf{1 1 1}$ & $\mathbf{1 0 0}$ \\
\hline
\end{tabular}

The above Table shows the data derived in reaction to four items (i.e. Items $1,2,3,4 \& 5$ ) in the questionnaire. Item 6 was represented to see whether or not students like to use translation during learning English. In this regard, majority of students (70(63\%) stated that they like to translate English into Amharic language during English lesson periods. Therefore, unlike some arguments put forward against the use of translation in a foreign language classroom [9] students view their teachers' translation use as an essential tool for English instruction and learning. Only (41(37\%) of the students responded that they do not want to use it.

\begin{tabular}{|l|l|l|l|l|}
\hline 7. & If 'Yes', how often do you like to use it (Say, in lesson period)? & a. fairly frequently & 50 & 71.4 \\
\cline { 3 - 5 } & b. sometimes & - & - \\
\hline & c. rarely & 20 & 28.6 \\
\cline { 3 - 5 } & d. never & 0 & 0 \\
\hline
\end{tabular}

In the seventh Item, that is an extension of the sixth one, was designed to look for information concerning how frequently students prefer to use Amharic language and translation in the English lesson periods. Accordingly, most of the respondents $(50(71.4 \%)$ replied that they like to use translation fairly frequently. Another significant number of students $(20(28.6 \%)$ also said that they sometimes use translation in one lesson period. However, the data, by and large, show that students like to use translation in English periods.

\begin{tabular}{|l|l|l|l|l|}
\hline 8 & $\begin{array}{l}\text { Do you think that translating English into Amharic language promotes your } \\
\text { English proficiency? }\end{array}$ & a. yes & 105 & 94.6 \\
\cline { 2 - 5 } & b. & no & 6 & 5.4 \\
\hline Total & & & 111 & 100 \\
\hline
\end{tabular}

The data presented under Item 8 show that a large proportion of students $(105(94.6 \%)$ responded that translating English into Amharic language promotes their English proficiency. These data agree with the argument proposed by [10] in that L1 can be an efficient tool for achieving students' comprehension and developing English language skills. But the remaining minority of students $(6(5.4 \%)$ revealed that translation should not be used in English classes. In relation to this, students, during focus group discussion session, pointed out that using translation and their first language develop their affinity to be motivated and learn English language well. Moreover, teachers' interview results also showed that students attend the lesson if and only if the target language teacher translates English into their mother tongue. One of the interviewees in Mengesha Jemberie school underlined by saying "What is the value of my teaching if students do not understand my presentation?"; therefore, students', as well as the teachers', opinion, in the whole, tells us that translating 
English into Amharic language promotes their English proficiency and learning the language.

\begin{tabular}{|c|c|c|c|c|}
\hline \multirow[t]{3}{*}{9} & \multirow[t]{3}{*}{$\begin{array}{l}\text { If 'Yes', to what extent do you know the grammar and } \\
\text { word structures of English and your first language? }\end{array}$} & $\begin{array}{l}\text { a. I can speak my mother } \\
\text { tongue and English well }\end{array}$ & - & - \\
\hline & & $\begin{array}{l}\text { b. I have a little change in } \\
\text { English language usage but } \\
\text { I cannot speak it well. }\end{array}$ & 54 & 51.4 \\
\hline & & $\begin{array}{l}\text { c. I will speak it well if I } \\
\text { practice it. }\end{array}$ & 51 & 48.6 \\
\hline & & & 105 & 100 \\
\hline
\end{tabular}

Item 9 is projected from Item 8 to see the students' opinion on the extent to which they know the rules of both English and their mother language. In this way, the data indicated a considerable number of problems with regard to the current know-how of an English language. According to this evidence, from the total students, no one can speak English and differentiate the grammar rules of English language. But (54(54.4\%) of the students responded that they have a little change in English language but cannot speak it whereas $(51(48.6 \%)$ of the students proposed for the future. Therefore, students lack the mastery of the rules and language skills in the target language, which in turn reveals the [11]'s argument forwarded against the use of translation in that translation by its definition has a very limited scope of objectives because speaking or any kind of spontaneous output was missing from the curriculum; students often fail at speaking or even writing in the target language. Therefore, Item 9 revealed as there are some pit falls in the use of translation as indicated by [11].

[Table item 10-17]: Responses to Items Designed to Get Students' Opinion on the Use of Translation in English Classroom.

[Note: $\mathbf{S A}=$ strongly agree; $\mathbf{A}=$ agree; $\mathbf{D}=$ disagree; $\mathbf{S D}=$ strongly disagree]

\begin{tabular}{|l|l|l|l|l|}
\hline Item no. & Questionnaire Items & Alternative & Freq. & \% \\
\hline \multirow{2}{*}{$\begin{array}{l}\text { If I do not compare the grammar of English with that of Amharic } \\
\text { language, I learn English faster. }\end{array}$} & a. & SA & 0 & 0 \\
\cline { 3 - 5 } & & b. A & 0 & 0 \\
\cline { 2 - 5 } & c. D & 30 & 27 \\
\cline { 2 - 5 } & d. SD & 81 & 73 \\
\hline Total & & $\mathbf{1 1 1}$ & $\mathbf{1 0 0}$ \\
\hline If any other, please specify & \multicolumn{3}{l}{} \\
\hline
\end{tabular}

As we can observe from item 10 , an overwhelming number of students $(81(73 \%)$ responded that they strongly disagree on the lack of comparison of students' L1 with that of English language. But very few number of students $(30(27 \%)$ agreed with disagreement on the non-comparative use of English and Amharic language. The researcher vividly attributes this argument to the fact that if they do not compare the grammar of English with their first language, it could be difficult to them to learn English. In connection to the above data, the literature evidence also shows that the two languages (i.e. English and the students' first language) may be connected through shared conceptual representations because of similar semantic content. Therefore, it is obvious to conclude here that English and the students' first language should be compared and clarified against each other so as to simplify difficult words and sentences to the foreign language learners.

\begin{tabular}{|l|l|l|l|l|}
\hline 11. & I learn faster when the grammatical rules of English are similar to the grammar of & a. SA & 100 & 90 \\
\cline { 3 - 5 } & Amharic language. & b. A & 11 & 10 \\
\cline { 3 - 5 } & & c. D & 0 & 0 \\
\cline { 3 - 5 } & d. SD & 0 & 0 \\
\hline
\end{tabular}

Item 11 indicates more different result than what the research evidences indicated on the grounds that there might be a great disparity between English language and the students' first language in terms of structure, lexis, and culture. However, a noticeable amount of students $(100(90 \%)$ responded that they strongly agree to learning faster when the grammar rules of English and their mother tongue are similar, whereas only $(11(10 \%)$ of the students agreed in the majority idea. Therefore, it seems worth mentioning here to state that language teachers believed to be required to take care of so many issues related to the target language text, culture and the learner.

\begin{tabular}{|c|c|c|c|c|c|}
\hline \multirow[t]{4}{*}{12} & \multirow{4}{*}{$\begin{array}{l}\text { Comparing the grammatical rules of Amharic language helps me to understand } \\
\text { similar rules of English language. }\end{array}$} & & $\mathrm{SA}$ & 74 & 66.7 \\
\hline & & b) & $\mathrm{A}$ & 30 & 27 \\
\hline & & c) & D & 7 & 6.3 \\
\hline & & d) & $\mathrm{SD}$ & 0 & 0 \\
\hline To & & & & 111 & 100 \\
\hline
\end{tabular}

According to the data presented under Item 12, large number of students (74(66.7\%) revealed that they strongly agreed to the concept of comparing similar grammatical rules of English and Amharic language. What the writer of this paper also speculates the reason why large number of respondents strongly agree on the concept of comparing similar rules of the two languages is that they strongly need the use of Amharic language in an 
English classrooms. The other proportion of students $(30(27 \%)$ also expressed their agreement on the given question. But only few students (7(6.3\%) argued that English and Amharic language should not be compared together. As the researcher conducted focus group discussion, some students, fewer in number, argue that translation and their mother tongue usage block their affinity to learn and master English language skills. However, it is not difficult to conclude that students, as the majority students argued, need their mother tongue and English to be compared together while they learn English.

\begin{tabular}{|l|l|l|l|l|}
\hline 13 & $\begin{array}{l}\text { I think explaining the grammatical rules of English and then showing how the } \\
\text { rules are different from my mother tongue will help me to avoid getting }\end{array}$ & 86 & 77.5 \\
\cline { 3 - 4 } & confused. & b) A & 20 & 18 \\
\cline { 2 - 4 } & c) D & 5 & 5.5 \\
\cline { 2 - 4 } & d) SD & 0 & 0 \\
\hline
\end{tabular}

According to the data presented under Item 13, a noticeable number of the students $(86(77.5 \%)$ strongly agreed on the idea of explaining the grammatical rules of English and then showing how the rules of the target language are different from their first language so as to avoid the possible confusions while the remaining few respondents $(20(18 \%)$ revealed their agreements to the question. But unnoticeable number $(5(4.5 \%)$ of the students replied that English and Amharic language should not be seen together. Therefore, as the researcher tried to infer from the students' evidence, the data revealed the [12] argument on the importance of the students' first language in an English classroom in that he described how translation and the students' first language can help to develop three characteristics essential for language learning: flexibility, accuracy, and clarity. [12](ibid) exemplified that translation trains the learners to search (flexibility) for the most appropriate word (accuracy) to convey what is meant (clarity). Thus, it is not vague to conclude here is that students' first language has a paramount importance on their learning of English language.

\begin{tabular}{|c|c|c|c|c|c|}
\hline \multirow[t]{4}{*}{14} & \multirow{4}{*}{$\begin{array}{l}\text { Translating English into Amharic language helps me to avoid making mistakes } \\
\text { when the rules of English are different from those of Amharic language. }\end{array}$} & & SA & 81 & 73 \\
\hline & & b) & A & 30 & 27 \\
\hline & & c) & D & 0 & 0 \\
\hline & & d) & SD & 0 & 0 \\
\hline \multicolumn{2}{|c|}{ Total } & & & 111 & 100 \\
\hline
\end{tabular}

The data put under Item 14 shows that a large percent of students (81(73\%) argued that translation helps students to avoid making mistakes when the rules of English are different from Amharic language and the remaining $(30(27 \%)$ of students also expressed their agreement on this item. These data boldly modified the [13] preposition in that translation, as a learning strategy, which helps students to develop ideas more easily and to express thoughts and opinions more clearly. Therefore, from data, again, it is to generalize that translation avoids making mistakes while students learn English.

\begin{tabular}{|c|c|c|c|c|c|}
\hline \multirow[t]{4}{*}{15} & \multirow{4}{*}{$\begin{array}{l}\text { Grammatical rules of English language should be explained in the same way to } \\
\text { different learners regardless of the grammar rules of Amharic language. }\end{array}$} & & & 4 & 3.6 \\
\hline & & & $\mathrm{A}$ & 2 & 1.8 \\
\hline & & & $\mathrm{D}$ & 35 & 31.6 \\
\hline & & d) & SD & 70 & 63 \\
\hline \multicolumn{2}{|c|}{ Total } & & & 111 & 100 \\
\hline
\end{tabular}

According to Item 15 , in the above table, a considerable number of respondents $(70(63 \%)$ argued that everything should not be explained in the same way for every student. As far as the researcher's understanding is concerned, students need the explanation of grammatical rules in different ways for different learners. It seems to be logical that every student may not have similar ability to understand and grasp what he/she is taught. Therefore, the data recommends different explanation techniques for different learners. The answer students provided with the open-ended item for the case of item 15 also revealed the same idea. The remaining $(35(31.6 \%)$ of the respondents also argued the same view while few unnoticeable number of students $(4(3.6 \%)$ and $(2(1.8 \%)$ show agreement with the idea of Item 15.

In contrast to the points, some considerable number of students revealed their attitude on the merits and demerits of translation. A few number of students, out of the total, argued that translation closes the road through which students can develop English speaking ability. With this argument, these few students, who discussed their views through open-ended item, touched what [11] stated concerning some common criticisms on translation in the ground that translation left learners with frustration when they travel to countries where the target language was used only to find they couldn't understand what the people were saying and tries to struggle mightily to express themselves at the most basic level. In this connection, students also responded that they could not talk using even a couple of English words after having learned through translation and mother tongue use. Students further noted that translation and the use of Amharic language made them not to know the deep and grassroots basic rules of English language. Therefore, what we can generalize from the students' response is that translation, not only important, but also it has a lot of drawbacks on the students' English language learning. Therefore, the researcher likes to recommend here that language teachers should take a great care and attention 
concerning the use of translation and the students' first language in such a way that students learn English better. [Tables for item 16 \& 17]: Responses of the Students' Opinion on the Major Problems Encountered in Translating English into Wolaita Language

\begin{tabular}{|c|c|c|c|c|}
\hline Item & & Alternatives & Fr. & $\%$ \\
\hline \multirow[t]{3}{*}{16.} & \multirow{3}{*}{$\begin{array}{l}\text { In your opinion, what kinds of } \\
\text { problems do you face when your } \\
\text { teacher translates English into } \\
\text { Amharic } \\
\text { language? }\end{array}$} & $\begin{array}{l}\text { a) It may interfere with my ability } \\
\text { to learn English well. }\end{array}$ & 26 & 23.4 \\
\hline & & b) Mismatch of the meaning of two languages. & 42 & 37.9 \\
\hline & & $\begin{array}{l}\text { c) I do not understand something when the } \\
\text { teacher translates and I usually ask other } \\
\text { students to make it clear. }\end{array}$ & 43 & 38.8 \\
\hline \multicolumn{3}{|c|}{ Total } & 111 & 100 \\
\hline
\end{tabular}

As can be observed from Item 16, almost equal number of respondents (42(37.9\%) and (43(38.8\%) argued that one of the major problems they encounter while learning the target language are mismatch of the meaning of the two languages and difficulty of concepts to understand English during teachers' translation respectively. In connection to this data, literature evidence reveals that these problems could be raised from the side of the language teacher rather than the students due to lack of the theoretical knowledge and technical skills of translation on the part of the translator [12:46]. The remaining few students $(26(23.4 \%)$ argued that translation interferes in their ability to learn the target language well. This has also its own literature evidence. For example, [15] cited in [2], argued that one of the important argument that led translation to have bad name was the fear of interference errors. Added to this, [15, ibid] further pointed out that translation poster a sense of false equivalence between the two languages resulting in inter-language errors. Therefore, translation seems to have a paramount negative effect on the students' English language learning if it is not used judiciously by the language teacher.

\begin{tabular}{|l|l|l|l|l|}
\hline 17 & $\begin{array}{l}\text { How difficult do you think it would be for you to understand } \\
\text { English lesson if your English teacher exclusively used English? }\end{array}$ & $\begin{array}{l}\text { a) extremely } \\
\text { difficult }\end{array}$ & 50 & 45 \\
\cline { 3 - 6 } & b) very difficult & 50 & 45 \\
\cline { 3 - 6 } & c) Difficult & 11 & 10 \\
\cline { 3 - 6 } & d) Not difficult & 0 & 0 \\
\hline \multicolumn{2}{|l|}{} & $\mathbf{1 1 1}$ & $\mathbf{1 0 0}$ \\
\hline
\end{tabular}

As can be observed from Item 17, all of the respondents revealed that it could be difficult for them to understand English lessons if their English teacher exclusively used English. Therefore, it is not difficult to conclude that students in the selected sample second cycle primary schools need their first language to be used as a language learning strategy on the grounds that their first language (Amharic) plays a scaffolding role in a collaborative task and can be a source of cognitive support. The students' response further indicates that they do not need their teacher to use without mixing English with their mother tongue.

Moreover, the researcher provided students an open-ended question 'if others please specify' option to derive the students' further outlook and opinion on the use of translation in English classes. Based on this, some students pointed out that not only word and sentence translation, but also students need an English text book that is translated in Amharic language. Their reason for this point is that they want to see the entire meaning of the target language text, culture and ways of expression in comparison to their L1 in such a way that it would help them to develop their English language using capacity at home, as well as in the school setting. However, another half of the students argued that English should be the only medium through which students interact with their teacher. Here, as the researcher's understanding is concerned, students who advocated little use of the students' L1 seems, unintentionally, to be in line with the argument that put forward for the natural use of the target language for virtually all communications as a sure sign of a good modern language learning. In relation to this argument, a few number of pupils also added that no matter how an English language is strange and difficult for them, they recommended, struggling to use only English is preferable rather than usually seeking teachers' translation in such a way that they could get an opportunity to practice an English language. However, another portion of students put forward their opinion against English-only approach in that students could not get any point whenever some teachers, whether it is intentionally or unintentionally, use English excluding the students' first language. It looks therefore sound to say that English teachers seem to use the students' L1 and translation so as to simplify new and difficult vocabulary words to develop the students' comprehension.

\subsection{Analysis of Audio-Taped Lessons} Introduction

The writer of this paper employed audio-taping as one of the data collection instruments in the grounds that it enabled him to capture scenes and interactions by means of tape-recorder because tape recorder was believed to 
be relevant in capturing the detailed information that might go unnoticed until scrutinized. To this end, lessons of three different English teachers were recorded, having one BA holder teacher from Mengesha Jemberie secondary School and two BA holder teachers from Shikudad secondary School. The selection of these teachers was based on the information that the researcher had been informed from both schools because these teachers were more open than others to be tape recorded and to provide genuine data. These teachers were considered as the role models for other teachers in that the school directors believed them honest to be tape recorded. Thus, the writer of this paper believes that the datum obtained through tape-recorder was unmodified, if not absolute. Then, the datum obtained in recording was converted into written form before being analyzed. Lessons recorded range in time from 45 to 47 minutes long. Having followed all these procedures, the researcher selected qualitative method to analyze tape-recorded lessons since qualitative method would show the possible problem of translation on the students' English language learning and would give the researcher an adequate opportunity to show the translation problem that has been discussed in the background of the study and the review of related literature section of this paper. The researcher further believes that qualitative method enabled him to give a comprehensive description and explanation of translation problems encountered by the students' learning in English classes. The relevance of this method for such purpose has been confirmed by [6].

\section{Summary of Audio-Taped Lessons}

Three English teachers' classroom lessons were audio-taped so as to get rich data on the translation activities conducted in the classroom. Recordings were carried out to find out the translation problems encountered on the students' learning of English and the extent to which teachers translate the target language into Amharic language. The focus of audio-taped lessons mainly inclined to answer the research questions 1,2 , and 4 on the grounds that these questions are more relevant to be investigated through audio-taped lessons than the research question 3. This is not to mean that research question 1, 2, and 4 cannot be seen in terms of the other tools. In this regard, teacher-1 used translation and the students' mother tongue more frequently than teacher 2 and 3. Moreover, the second teacher's classroom discourse showed some possible problems could be encountered in language classes. His discourse more clarified the issues associated with the semantic relatedness in translation mentioned by scholars. In relation to this scenario, some few numbers of teachers also pointed out the same problem mentioned under subtitles "semantic relatedness" and "the problems in language translation" in literature. Some student respondents, though the majority advocates mother tongue use, revealed that using students' L1 may have some hampering influences on their learning. Therefore, what we can see is that overimplementation of the students' first language might have some negative consequences on English learning. One important issue that the writer of this study also likes to point out is that translating some strange words and sentences into the students' L1 should be allowed. For example, teacher-1 translated an English term "treasure" into Amharic language as "genzeb (tirit)" This could be useful for learners to know the word. But overimplementation might have a humiliating factor on the students' English language learning and their English vocabulary. From the writer's understanding, translation and L1 use, if used minimally, seem not to be banned in English classroom because the data obtained through different tools indicated that translation has a positive effect on the students' learning. However, the study shows that its problem on language learning should not be seen as simple issue but care should be taken.

No matter how translation is seen as evil for English language learning, the second teacher's discourse indicated that the use of L1 seems to be relevant on teaching passive and active voice. But something that should also be disclosed here is that the second teacher should have discussed exclusively in English up to certain extent before introducing students' L1 so as to give opportunity for students to listen and practice English language. Otherwise, it could be strange to say that students learn English. The researcher likes to prefer teacher 2 and 3's techniques of classroom discourse in that they employed much time for the target language usage than what teacher one did.

By and large, as it has been stated in the three teachers' moves, the classroom interaction was dominated by the teacher. The data do not show when students take an optimum part in the classroom, which in turn reflects the issues criticized in the Grammar Translation Method (GTM).

\subsection{Results of an Interview Data with Teachers}

The three secondary school teachers, one teacher from Mengesha Jemberie secondary school and two teachers from Shikudad secondary school were asked about the influence of the use of translation in English classroom. One teacher intentionally selected from Mengesha Jemberie based on the familiarity of the teacher with the researcher because he knows the researcher due to home proximity. Based on this selection, the researcher believes that he has derived pertinent data for 8 semi-structured interview questions. Five of the questions were designed based on the different arguments forwarded concerning the use of translation in English classes so as to draw literature based answers from interviewees. In reaction to how teachers view the scholar's argument that using translation reduces the students' exposure to the target language, the first teacher responded that, 
“Students' first language and translation should not be used in an English classroom because it may, undoubtedly, affect the students' future language development in every aspect of educational program." Some of the drawbacks, if translation is used in English classes, that the teacher (interviewee) mentioned are: "students could not express themselves in the language they are taught; students' L1 and translation have no sound positive value on the students' English language learning rather it was believed to be killing agent for the language learners; students who were taught through translation face a lot of challenges when they come to their birth place to serve their society because they could not teach English language after completing their higher education due to lack of the target language competence; they could not express themselves in an English language ; they could not speak and write well in English language. Therefore, people insult them." The first teacher further noted, as being emotional, that students did not learn in an inclusive language. Due to this reason, they fail to give inclusive service for the society. He again added that the value of learning English seems to have gone down grounds that students fail to use English back when they return to give service. The teacher expressed his own worry as follows: "Some urban kindergarten students use English much more than students who come from rural areas in that urban students take due attention, especially in English subjects." What we can infer from this much of the teachers' argument is that translation could have its own side effects on the students' learning of an English language.

However, the second teacher forwarded different answers. Hence, he focused on the purpose of teaching the language itself. He noted that the major objective of language teaching is to make students understand what they learn. In this regard, he noted that students' L1 and translation make everything clear for students. Therefore, as he added, translation should be encouraged unless students do not understand what they are learning. Teacher 2 , further verified that students come from their home with their L1. They did not have any target language repertoire. Therefore, translation is mandatory, as explained by teacher 2, to be used to make unfamiliar English language familiar for students. Moreover, the teacher raised the issue of teachers' language skill. In this connection, he criticized himself "How far am I ready and confident enough to teach grade 8 students?" Accordingly, he argued that teachers' ability should be taken into consideration when the issue of translation is raised. The researcher believes that the second teacher, during the interview time raised what the literature evidence shows. To cite some research evidence here, [4] noted that translation is not an easy task. In this connection, [16] says that good language translation cannot be achieved without the mastery of the second language. But, as the researcher believes, not all teachers master both the mother tongue and the second language equally well. Teacher 2 further forwarded similar answer. He, in fact, focused on the time span in which teachers train to be a language teacher. He noted that teachers who are trained within one or two years' life could not teach and train students well as required. In replying to the second item, he revealed that students become very excited when English teachers translate the target language into Amharic language during learning. In responding to the fourth question, "How do you see the argument that using translation reduces students' exposure to the target language?" He responded that using only translation has a lot of weak sides. Two of them are:1) It makes students passive; 2) It kills the students' language skills.

Teacher 3, in contrast to some arguments of teachers 1 and 2, argued that translating difficult English words into simple English is preferable. He again described that leaving tasks for students themselves is important in that students read, try and dig out the right way of language learning in their own ways. In this connection, he said, indicating the location of some reference books is also believed to be important. Teacher two provided an example in showing the bad sides of translation. He said that if the teacher translates the word 'book' in to Amharic language as 'metshaf', students would say 'metsaf?', which is translated back into English writing. 'is it?' or in Amharic 'new inde?' and they pass it because it was not the result of their hard working. Therefore, he concluded that translation has some weak sides to use as the sole way of English teaching.

When an interviewee was discussing about the language teachers' competence, he said, "Teachers due to lack of language skill, they jump into Amharic language." Teacher 2 noted the reason for this problem in that teachers could not use English fully because they are the result of the past generations. The next reason that the teacher raised as a question should be quoted here in that "How language teachers possess good command of English within one year training?" The teacher suggested that giving some extra training service for the language teachers is important. The teacher also did not disclose the advantage of using translation. He replied, "If there is no translation, students could not understand the language." Therefore, he noted that it does not mean that translation should be banned rather its frequency should be limited to some extent.

Teacher 3, on the other hand, reported that first of all, it could be difficult for the pupils to comprehend anything when the teacher teaches using only English. He said that through long time training and use of only English language, students could develop the ability of using English language and become confident enough to learn using only English. Teacher 3 again argued that language teachers should serve first some difficult vocabulary words. Then, it would get difficult for learners, he again provide with less difficult and simple English for the next time so as to familiarize students the English language use in such a way that students wouldn't be addicted by teachers' translation. Teacher 3's argument is that when the teachers' presentation is 
only in English, students start to understand little by little and they would become knowledgeable in speaking, writing, reading and listening if every discourse becomes only in English. But the interview conducted with teacher 3 again showed that students may not feel that he is teaching them very well if he uses only English.

\subsection{Results of Focus Group Discussion (FGD) with Students}

The writer of this paper held discussions with a group of students in the two selected schools. No matter how each of the groups held discussions with the researcher on different days, what all of them said about the use of translation in the target language classroom were almost the same. The first question posed for discussion was the type of language that grade 9 English teachers use while teaching English. Almost all of them, except little unnoticeable number of students, revealed that their target language teacher uses Amharic language as a medium of instruction. And the writer of this paper added a follow up question for the target group students. "Which language do you prefer most and why?" Students responded that they need both English and Amharic language together, otherwise, they added, it could be difficult for them to get what the teacher is saying. Another member of the group said that English teachers, most of the time, use English language, but they need English language to be translated to their L1. They also verified that they ask their English teacher to translate some difficult words and sentences for them. Another argument put forward by the discussion groups is that it could be bad if the teacher exclusively uses their mother tongue on the grounds that they could not get any possible method to train English language. In response to question 5, students revealed that they have a doubt to say that the translation usage of all teachers is clear. [17], in connection to the translation and the related problem stated that alien concepts which cannot be easily translated into a particular language and dialect differences and lack of standard usage for some words are among the key problems which affect the quality of students' language learning. For the sixth question, the target groups provided the same response in that they ask their English teacher to translate English language into Amharic language until it becomes clear for them. From this evidence, we can also deduce that the students overtly need English language to be translated into their mother tongue. Students gave the same response to the seventh question as they did in the questionnaire session in that the possible negative effect, if used entirely, of translation is that it affects the students' ability of developing the target language skills. This argument could be substantiated with the [18]'s argument in that a number of serious objections, the main problem being lack of everyday realistic spoken language content, have been raised with regard to the grammar translation method.

Generally, discussion groups further responded that teachers use translation and the students' L1 when students become silent when they were asked about the day's lesson. But, as it was pointed out in the interview with English teachers, language teachers use translation, as well as the students' first language because of lack of English speaking competence. They boldly pointed out that the setting where they live; the community itself; and the general socio-economic problems they face day-to-day adversely affect the target language teachers' ability to teach their students and to use the language itself as well. Some of the interviewees (teachers) again said that even they are facing some challenges to compete with the existing situations in universities when they join higher education program. Finally, teachers asked the researcher to show the direction through which they can develop English language speaking ability. The majority of the student interviewees argued that they hate the teachers who usually use only English and they consider such teachers as boasting. Another half of the students also asserted that teachers' translation and their mother tongue usage is their own criterion to differentiate a teacher as good and bad, i.e. if the teacher does not use their first language they automatically hate him. On the other hand, they also like teachers who use their mother tongue. The researcher's background experience also shows the same cases with what the students argued concerning the use of translation and their mother tongue in English classrooms. Therefore, it looks possible to generalize that students, individually through questionnaire; in group through focus group discussion, need translation and their mother tongue on the learning of English language.

\section{FINDINGS}

Four research questions were addressed in this study, and the principal findings suggested that 1) most participants, especially learners approved that translation plays a positive role in their English learning experiences, but participants also had conflicting arguments about translation, resulting from their different understandings of both positive and negative effects of using translation. On the whole, translation seems to play an important facilitative role in second cycle primary schools students' English language learning processes. According to students' shared opinions about using translation in learning English, generally they expressed the inevitability of translation use at their current stage of learning, and see translation as a positive learning resource for them to comprehend and learn better English. However, some teachers also showed a somewhat contradictory feeling towards translation. On the one hand, they apparently believed that without translation, it is unlikely to make students learn the language. Teachers were also concerned that translation might 1) close the way through which students could develop English learning opportunity 2) inhibit students' thinking in English 
3) make learners assume that there is a one-to-one correspondence of meaning between English and Amharic, and thus become a 'bottle neck' on students' advancement in English learning. As a result, some respondents believed that they should gradually refrain from using translation as a learning tool of English. Another major finding of this work indicated that teachers may not need to ban the use of translation on English learning altogether and they should be more aware of the occasions when translation can be more beneficial to the students' English learning. This had also been reflected on Students' FGD results in that students expressed that they need translation whenever it is essential. Both teachers and students agreed that English teachers should use translation sometimes. The study further revealed that students believe in the various pedagogic use of translation and their mother tongue in that translation and the use of L1 help them to know difficult concepts; understand new vocabulary items; make learners feel at ease, comfortable and less stressed. An overwhelming number of participants, moreover, did not advocate the idea of the total rejection of mother tongue and translation usage in English classroom. This, in turn implies that an exclusive English-use theory [19] in English learning could hamper the possible students' English learning ability. The majority of the respondents argued the importance of translation. However, the data obtained through an audio-taped lessons and classroom observation exhibited that there was a mismatch of meaning between translated and English expressions due to the influence of lack of appropriate language training service for English teachers and teachers' lack of exposure to the target language speaking community put forward for inefficiency.

Even though some unnoticeable number of students and teachers did not like the use of translation and students' L1 in the classroom, the responses gained from all students through questionnaire and FGDs, as well as the data obtained from majority of teachers $(4(66.7 \%)$, out of $(6(100 \%)$, and classroom observation revealed that students have a great tendency to learn English well when some difficult vocabularies, phrases and sentences are translated into Amharic language. But these respondents also disclosed the possible problems that could be encountered on English learning if the teachers exclusively used Amharic language as a medium of instruction. This fact seems to outlaw Ellis's (1985) view of exclusive-English using theory on English language teaching and learning

Thus, even if translation and mother tongue use have been criticized by majority of scholars [19]; [11]; [3]; [120]; and [21:350], etc) and some participants, it is found to be useful because it prepares for or consolidates activities by relating L2 to L1. It builds on what learners already know about the usage of their L1 to build up their knowledge of how to use the English language. From the arguments that have been put on in this study, it is not difficult to see the effects of the use of students' mother tongue and translation on foreign language learning. However, we cannot generalize from this limited data, such weaknesses are very likely to be seen in other similar schools, and therefore, it is reasonable to put some suggestions. If English is to be used as a dominant medium of instruction in schools, there should be restructuring programmes so as to strengthen the position of teaching and learning the language in schools. It has also clearly been stated in this paper that teachers take too much time explaining structures (doing grammar analysis) to the students who know very limited number of English words. A part of these times could better be spent in practicing language skills in English.

\section{CONCLUSION}

Using translation, such as word for word translation, inter-linguistic translation, intra-linguistic translation, and inter-semiotic translation, the language teacher can exploit translation both as an exercise which sharpens students' perceptions about language contrasts and as one which increases their feeling for communicative appropriateness in English. There was also an assumption that translation builds usefully on English language competence that students already have, and that the problem solving nature of translation makes it a motivating activity; it has also been argued by sample teachers that it has a sensible role to play in the teaching of students. The data has also shown that majority of English teachers use translation and Amharic language in their lesson periods. Teachers themselves also pointed out that they use the students' L1 as resource for English language teaching. Thus, the study indicated that students have developed the habit of hearing in English and saying things in Amharic. Teachers' data further indicated that they use Amharic language dominantly as a medium of instruction because students need translation and their mother tongue. We can take tabulated items $1,3,6,8$, and 17 in that an overwhelming number of students answered that they need translation and their mother tongue. Otherwise, according to the data, they couldn't get what the teacher says. However, the participant teachers did not disclose the possible problems that could happen when they dominantly employ students' first language as a medium of instruction. The study also shows that the pupils are unlikely to learn English with this proficiency, and neither the teachers teach them efficiently. Translation, in contrast to some proponents, such as [19]- [12]]; [12], etc, does not work any even if students were to accept it in principle, for it has been found out that the sentences and words often are mistranslated and confuse concepts (as stated in the literature review by the title "semantic relatedness in translation") while translating. In this regard, it is not difficult to see the effects of the use of translation on English learning. Moreover, the minority of the students' evidence and the views given by authorities regarding the impact of excessive use of vernacular is obvious and convincing. However, the data 
magnificently indicated that in the selected second cycle primary schools, students need their teachers to translate and use their own mother tongue in English classroom. For instance, questionnaire items, such as items $1,2,4,6,7,8,10,12, \& 13$, revealed that almost all students need English language to be translated into Amharic language. Information obtained through focus group discussion with pupils also showed the same value though a small number of students hate translation and the use of their mother tongue in English class.

The study also recommended that translating English text books into the students' L1 would have a paramount importance on the students' ability to learn the target language. In addition, it is necessary to consider some impacts of an over-implementation of translation and the students' first language in a classroom.

\section{Acknowledgements}

I sincerely thank all my friends for their proof reading the manuscript. My appreciation goes to my lovely wife and child for their love, patience and never ending support while I was doing this and other papers.

\section{REFERENCES}

[1]. Kenenissa (2003). Using L1 in the EFL classroom: The case of language with Particular reference to Adama Teachers' College. MA thesis (Unpublished).

[2]. Cook, V. (2001).Second Language Learning and Language Teaching. New York: Oxford University Press, Inc.[3]. Edge, J.(1986). Acquiring Disappears in Adultery: Interaction in Translation Class. ELT Journal, 40/2,121-124.

[4]. Tafesse Geleta(1988). The Use of Vernacular in Teaching English: A survey of Addis Ababa Zone Four Junior Secondary Schools. MA Thesis, Addia Ababa University (Unpublished).

[5]. Seliger,H.W.and Shohamy,E.(1989).Second Language Research Methods. Oxford: UP.

[6] Mertler, C.A. and Charles, C.M. (2005). Introduction to Educational Research (5 ${ }^{\text {th }}$ Ed.). New York: Pearson Education, Inc.

[7] Gall, J.P. and Walter,R.B. (1996). Educational Research: An Introduction (6 ${ }^{\text {th }}$ Ed.). White Plains, New York: Longman Publishers, USA.

[8] Koul, L. (1993). Methodology of Educational Research (3 ${ }^{\text {rd Revised }}$ Ed.). New Delhi:Vishal Printers.

[9] Atkinson, D. (1986). The Mother Tongue in the Classroom: A Neglected Resource? ELT Journal, 41/4,241247.

[10] Auerbach,E.(1993).Re-examining English Only in the Classroom. TESOLQuarterly,Vol .27,9- 32.

[11] Brown, H.D. (2001). Teaching by Principles: An Interactive Approach to Language Pedagogy (2 $2^{\text {nd }}$ Ed.). White plains, New York: Longman.Candlin.

[12] Duff, A. (1989). Translation: Resource Books for Teachers. Oxford: OUP.

[13] Liao,p.s.(2002). EFL Learners' Belief about and Strategy Use of Translation In English Learning. Department of Foreign Languages and Applied Linguistics. Taiwan: National Taipei University, posen@mail.ntpu.edu.+w.

[14] Belachew W/Gebriel (2007). Literary Translation: Stylistic and Cultural Accommodation in Translation of Sydney Sheldon's The Sky is falling into Amharic Dana. Department of Foreign Language and Literature, Addis Ababa University MA Thesis (Unpublished).

[15] King, J. (2001). Language and Translation.Vol.13, 1-9. New Delhi: Saudi University.Vol.13, PP.1-9 (AH.1421/2001).

[16] Lado, R. (1964). Language Teaching: A Scientific Approach. New York:McGraw Hill,Inc.

[17] McNabb,C.(1989). Language Policy and Language Practice: Implementation Dilemmas in Ethiopian Education. Stockholm: Stockholm University.

[18] Harmer, J. (1991). The Practice of English Language Teaching. London: Longman.

[19] Ellis, R. (1985).Understanding Second Language Acquisition. Oxford : OUP.

[20] Widdowson, H.(1987). Teaching Language as Communication. Oxford : Oxford University Press.

[21] Harbord, J. (1992). The Use of Mother Tongue in the Classroom. ELT Journal, V.46, 4, 350-55. 